\title{
Morphological change of the acrosome on motile bovine spermatozoa due to storage at $4^{\circ} \mathrm{C}^{*}$
}

\author{
E. P. Aalseth $\dagger$ and R. G. Saacke \\ Department of Dairy Science, Virginia Polytechnic Institute and State University, Blacksburg, \\ Virginia 24061, U.S.A.
}

\begin{abstract}
Summary. Swelling of the apical ridge and anterior acrosome of motile bovine spermatozoa was observed during in-vitro storage using differential interferencecontrast optics. This morphological alteration is different from that described as the false acrosome reaction on immotile spermatozoa, apparent in ageing semen samples and which has been associated with cell death. In this study, transmission electron microscopy revealed that the apical ridge acrosomal matrix was extended into complex folds and/or projections. Acrosomal and plasma membrane integrity was retained. Storing spermatozoa $\left(1500 \times 10^{6} / \mathrm{ml}\right)$ in seminal plasma at $4^{\circ} \mathrm{C}$ for 1 day was most conducive to the swelling of the apical ridge. Replacing seminal plasma with egg yolkcitrate inhibited swelling. However, incubating semen at $37^{\circ} \mathrm{C}$ in egg yolk-Trisfructose extender $\left(25 \times 10^{6}\right.$ spermatozoa/ml $)$ after storage in egg yolk-citrate at $4^{\circ} \mathrm{C}$ for $\geqslant 3$ days restored the swelling characteristic.
\end{abstract}

\section{Introduction}

The false acrosome reaction (Bedford, 1970) constitutes acrosomal changes occurring in association with sperm death and/or irreversible injury. Using electron, bright field and differential interference-contrast microscopy, these changes have been characterized for bovine spermatozoa (Saacke \& Marshall, 1968).

The false acrosome reaction can be quantified using differential interference-contrast microscopy on unfixed wet smears (Robbins, Saacke \& Chandler, 1976; Aalseth, Senger \& Becker, 1978; Almquist \& Landa, 1980) and on fixed wet smears (Johnson, Berndtson \& Pickett, 1976; Mitchell, Hanson \& Fleming, 1978), thus providing an objective means for evaluating semen viability. For bovine semen, this technique is made easier by the very distinct apical ridge (enlargement of the acrosome along the anterior margin of the sperm head) which is apparent on viable spermatozoa examined by differential interference contrast microscopy. The abrupt disappearance of this structure at the onset of the false reaction, as it occurs on immotile bovine spermatozoa (Saacke \& Marshall, 1968), provides a sharp irreversible end-point for sperm viability.

The use of acrosomal morphology to quantify semen viability of bulls is supported by its relatively good relationship with fertility of preserved $\left(-196^{\circ} \mathrm{C}\right)$ semen (Saacke \& White, 1972; Saacke $e t$ al., 1980). Consequently, it has been frequently used by the artificial insemination industry as a quality control characteristic. However, situations have occurred when loss of the apical ridge was not abrupt, making quantitative assessment difficult. Pace, Sullivan, Elliott, Graham \& Coulter (1981) found that the apical ridge could become swollen or ruffled: since the

\footnotetext{
* Reprint requests to Professor R. G. Saacke.

$\dagger$ Present address: Department of Animal Science, Oklahoma State University, Stillwater, Oklahoma 74078. U.S.A.
} 
status of such spermatozoa was not known, they were classified as injured. A similar intermediate condition of the acrosome was encountered in our laboratory on a high proportion of motile spermatozoa. The objectives of this study were (1) to characterize morphologically the acrosomal change (swelling), and (2) to identify the major environmental requirements for bovine spermatozoa to exhibit this property.

\section{Materials and Methods}

Swelling of the apical ridge (SAR) on motile spermatozoa was first observed in our laboratory after neat semen had been slowly cooled to $4^{\circ} \mathrm{C}$, stored for 1 day, and then extended and incubated at $37^{\circ} \mathrm{C}$ in an isotonic Tris (hydroxy-methylaminomethane)-fructose medium. This experiment was conducted to determine the relative importance of the following environmental conditions on SAR: (1) the presence of seminal plasma during $4^{\circ} \mathrm{C}$ storage, (2) the length of storage at $4^{\circ} \mathrm{C}$, (3) the influence of $37^{\circ} \mathrm{C}$ incubation in a Tris-fructose based medium, and (4) duration of $37^{\circ} \mathrm{C}$ incubation.

Semen storage and incubation media. Semen was stored $\left(4^{\circ} \mathrm{C}\right)$ in seminal plasma or the conventional egg yolk-citrate extender composed of $20 \%(\mathrm{v} / \mathrm{v})$ egg yolk (Gallus domesticus) and $80 \%$ $98.6 \mathrm{~mm}$-sodium citrate. After storage, semen incubation at $37^{\circ} \mathrm{C}$ was in egg yolk-citrate or egg yolk-Tris-fructose composed of $20 \%(\mathrm{v} / \mathrm{v}) \mathrm{egg}$ yolk and $80 \%(\mathrm{v} / \mathrm{v})$ of a buffer containing $235 \mathrm{mM}$ Tris base (Sigma), 54 mm-fructose and $72 \mathrm{~mm}$-citric acid. Each medium also contained 1000 i.u. penicillin and $1000 \mu \mathrm{g}$ dihydrostreptomycin sulphate $/ \mathrm{ml}$. Both egg yolk extenders were adjusted to pH 6.8 with citric acid and centrifuged at $15000 \mathrm{~g}$ for $5 \mathrm{~min}$ to remove particulate matter. For all media, osmolarities based on freezing point depression were within a 272-278 mosmol range.

Experimental protocol. Three ejaculates, each from a different bull, were collected by artificial vagina, pooled and allowed to reach room temperature. An aliquant of the pooled semen was centrifuged at $3900 \mathrm{~g}$ for $5 \mathrm{~min}$ and seminal plasma was recovered. Sperm concentration of the remaining semen was determined turbidimetrically and adjusted to $1500 \times 10^{6}$ spermatozoa/ml by addition of seminal plasma. One half of this adjusted semen was washed 3 times with egg yolkcitrate $(1: 4 \mathrm{v} / \mathrm{v})$ to replace seminal plasma. Each washing included centrifugation at $1000 \mathrm{~g}$ for 5 min, aspiration of supernatant and resuspension in egg yolk-citrate, and restoration of the final suspension to $1500 \times 10^{6}$ spermatozoa $/ \mathrm{ml}$. Then spermatozoa in seminal plasma or egg yolkcitrate at $1500 \times 10^{6}$ spermatozoa/ml were uniformly cooled to $4^{\circ} \mathrm{C}$ in $5 \cdot 5 \mathrm{~h}$. After 1,3 and 5 days of storage, aliquants of samples in each treatment were extended to $25 \times 10^{6}$ spermatozoa $/ \mathrm{ml}$ in egg yolk-citrate or yolk-Tris-fructose and incubated at $37^{\circ} \mathrm{C}$. After $5 \mathrm{~min}, 2 \mathrm{~h}$ and $4 \mathrm{~h}$ of incubation, the spermatozoa were subjectively evaluated for percentage motile and proportion of motile spermatozoa exhibiting SAR ( $0-3$ scale). Spermatozoa were considered motile regardless of the form; however, progressive motility was the predominant form amonst the treatments studied. A phase-contrast microscope $(\times 100)$ equipped with a heated stage was used for motility evaluation. A differential interference-contrast microscope $(\times 1250)$ was used to detect acrosomal change. A scale value assigned for the estimated proportion of motile spermatozoa exhibiting SAR was: $0=$ $<5 \% ; 1=5-25 \% ; 2=26-50 \%$; or $3=>50 \%$. In our judgement, this scale represented the best subjective measure possible for characterizing treatments by morphology of the apical ridge on motile spermatozoa. The experiment was replicated 3 times. Before analysis of variance (Goodnight, 1979) data were transformed for statistical analysis with the following formulas: $2 \times$ the square root of the arcsin for percentage motility and the square root of (SAR $+0 \cdot 5)$ for SAR.

Morphological characterization. Spermatozoa for morphological evaluation using transmission electron microscopy were obtained from a treatment that yielded the highest level of SAR (graded 3 ), i.e. semen stored $\left(4^{\circ} \mathrm{C}\right)$ for 1 day in seminal plasma followed by extension in the egg yolk-Tris- 


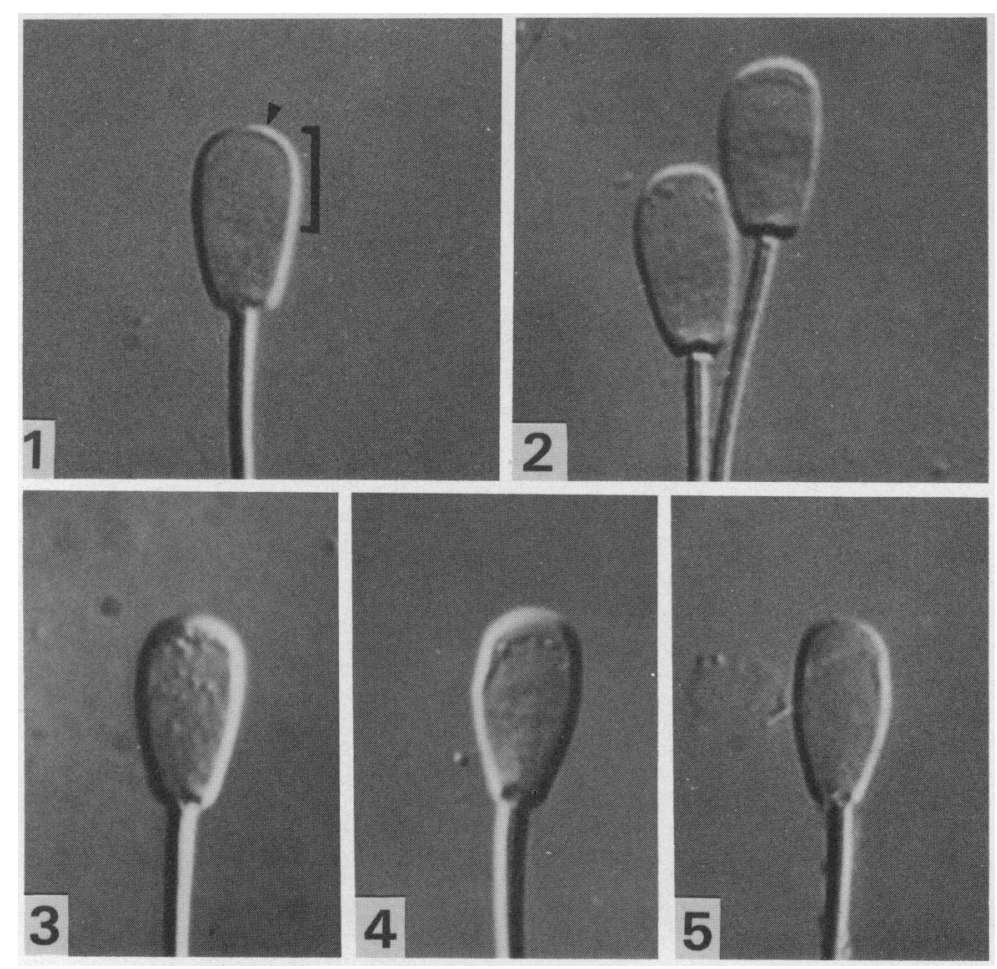

Differential interference-contrast micrographs of heads of bull spermatozoa. $\times 2000$.

Fig. 1. Acrosomal morphology of a normal (control) spermatozoon. Note that distinct smooth crescent shape of the apical ridge (arrowhead) and the smooth acrosomal surface.

Fig. 2. Sperm heads showing early and moderate forms of swollen apical ridge. Note the posterior expansion in the apical ridge region.

Fig. 3. Sperm head showing moderate swelling of apical ridge and small irregularities on the acrosomal surface.

Fig. 4. Sperm head showing more extensive swelling of the apical ridge. Note the involvement of the lateral edges of the acrosome. Small irregularities are also present on the acrosomal surface.

Fig. 5. Sperm head showing the maximum degree of swelling of the apical ridge observed in these studies. 
PLATE 2
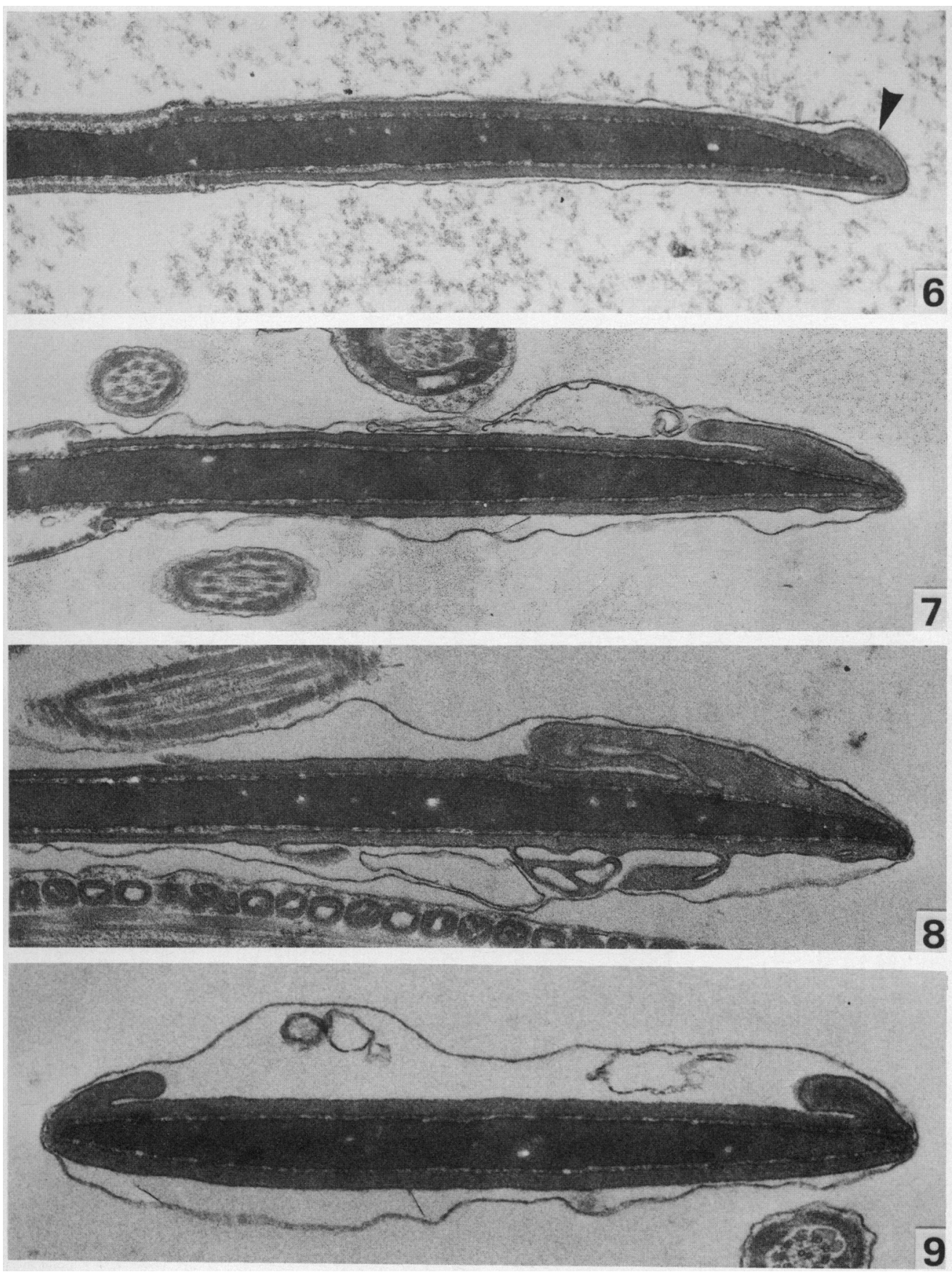
fructose medium and incubation for $2 \mathrm{~h}$ at $37^{\circ} \mathrm{C}$. For comparison, spermatozoa without SAR were obtained from a treatment yielding the lowest level of SAR (graded 0), i.e. semen stored at $4^{\circ} \mathrm{C}$ for 1 day in egg yolk-citrate followed by extension in egg yolk-citrate and incubation for $2 \mathrm{~h}$ at $37^{\circ} \mathrm{C}$. For electron microscopy, spermatozoa were reconcentrated from each of these treatments by centrifugation at $1000 \mathrm{~g}$ for $5 \mathrm{~min}$ forming a flocculant pellet which was resuspended in Karnovsky's fixative (Karnovsky, 1965) for $30 \mathrm{~min}$. After centrifugation at $1700 \mathrm{~g}$, the pelleted spermatozoa were rinsed in $0.1 \mathrm{M}$-sodium phosphate buffer, osmicated and treated with tannic acid (Simionescu \& Simionescu, 1976). Spermatozoa were dehydrated, embedded in Epon 812-araldite, thinly sectioned and stained with uranyl acetate and lead citrate (Venable \& Coggeshall, 1965).

Differential interference-contrast photomicrographs were taken of spermatozoa from comparable treatments after motility was arrested by adding, to $1 \mathrm{ml}$ semen, $10 \mu \mathrm{l} 5 \%(\mathrm{w} / \mathrm{v})$ paraformaldehyde in phosphate-buffered saline (0.1 M-sodium phosphate, $137 \mathrm{~mm}-\mathrm{NaCl}, \mathrm{pH} 6 \cdot 9)$.

\section{Results}

Samples prepared for morphological evaluation were examined for SAR. A maximum SAR response ( 3 rating) was observed in samples expected to have SAR and no SAR was observed in control samples. Under differential interference-contrast microscopy, the head of a normal live spermatozoon (control) has a smooth acrosomal surface and a distinct crescent-shaped apical ridge (Pl. 1, Fig. 1; Saacke \& Marshall, 1968). In contrast, spermatozoa exhibiting SAR displayed a range of apical ridge expansion (Pl. 1, Figs 2-5). Other modifications of the anterior acrosomal region associated with SAR were small irregularities on the flat surface (Pl. 1, Figs $3 \& 4$ ) and expansion of the lateral edge of the acrosome (Pl. 1, Figs 4 \& 5).

Electron microscopy confirmed the morphology observed with the light microscope. Ultrastructural comparison to a normal spermatozoon (PI. 2, Fig. 6) indicated that those with swelling (Pl. 2, Figs $7 \& 8$ ) possessed an anterior acrosomal matrix that was expanded posteriorly into folds and projections. Alteration of the acrosomal matrix varied from moderate (Pl. 2, Fig. 7) to complex (Pl. 2, Fig. 8) and involved the lateral edges of the acrosome (Pl. 2, Fig. 9). The integrity of the plasma membrane and outer acrosomal membrane appeared to be maintained regardless of the complexity of SAR (PI. 2, Figs 7-9).

The effects of conditions studied on SAR and motility are presented in Table 1. Storage media, incubation media, and incubation interval interacted $(P<0.05)$ in producing SAR. SAR was most pronounced ( 3 rating) in semen that had been stored in seminal plasma for $1-5$ days at $4^{\circ} \mathrm{C}$ regardless of incubation medium or duration of incubation. However, when spermatozoa were stored in egg yolk-citrate and subsequently extended and incubated at $37^{\circ} \mathrm{C}$ in egg yolk-citrate,

\section{PLATE 2}

Transmission electron micrographs of the heads of bull spermatozoa. $\times 26000$.

Fig. 6. Morphology of the acrosome from a sagittal section of a normal sperm head (control). Note the small but distinct apical ridge (arrowhead).

Fig. 7. A sagittal section of moderate anterior acrosomal swelling. Note the posterior expansion of the apical ridge as it folds back over the acrosomal surface. The outer acrosomal and plasma membranes are intact.

Fig. 8. A sagittal section showing extensive anterior acrosomal swelling. Note the expansion and complex folding of the apical ridge. It was also evident that swelling can develop on both sides of the acrosome. The outer acrosomal membrane was intact as it covered the complex acrosomal surface. Plasma membrane integrity was also apparent.

Fig. 9. A cross-section in the anterior acrosomal region showing expansion of the lateral edges of the acrosome. 
Table 1. Effect of storage medium, length of storage at $4^{\circ} \mathrm{C}$, incubation medium, and duration of incubation on (a) swelling of the apical ridge (SAR) of bull spermatozoa and (b) their percentage motility

\begin{tabular}{|c|c|c|c|c|c|c|c|}
\hline \multirow{3}{*}{$\begin{array}{l}\text { Incubation } \\
\text { medium }\end{array}$} & \multirow{3}{*}{$\begin{array}{l}\text { Incubation time } \\
\qquad\left(37^{\circ} \mathrm{C}\right)\end{array}$} & \multicolumn{6}{|c|}{ Storage medium } \\
\hline & & \multicolumn{3}{|c|}{ Seminal plasma } & \multicolumn{3}{|c|}{ Egg yolk-citrate } \\
\hline & & 1 day & 3 days & 5 days & 1 day & 3 days & 5 days \\
\hline (a) Egg yolk-citrate & $\begin{array}{l}5 \mathrm{~min} \\
2 \mathrm{~h} \\
4 \mathrm{~h}\end{array}$ & $\begin{array}{l}3.0 \\
3.0 \\
3.0\end{array}$ & $\begin{array}{l}3 \cdot 0 \\
3 \cdot 0^{*} \\
-\dagger\end{array}$ & $\begin{array}{r}3.0 \\
-\dagger \\
-\dagger\end{array}$ & $\begin{array}{l}0.0 \\
0.0 \\
0.0\end{array}$ & $\begin{array}{l}0.3 \\
1.0 \\
0.7\end{array}$ & $\begin{array}{l}0.3 \\
1.0 \\
0.7\end{array}$ \\
\hline Egg yolk-Tris-fructose & $\begin{array}{l}5 \mathrm{~min} \\
2 \mathrm{~h} \\
4 \mathrm{~h}\end{array}$ & $\begin{array}{l}3 \cdot 0 \\
3 \cdot 0 \\
3 \cdot 0\end{array}$ & $\begin{array}{l}3.0 \\
3.0 \\
3.0\end{array}$ & $\begin{array}{l}3.0 \\
3.0 \\
-\dagger\end{array}$ & $\begin{array}{l}0.0 \\
0.7 \\
1.7\end{array}$ & $\begin{array}{l}0 \cdot 3 \\
2 \cdot 3 \\
2 \cdot 7\end{array}$ & $\begin{array}{l}0.7 \\
3.0 \\
3.0\end{array}$ \\
\hline (b) Egg yolk-citrate & $\begin{array}{l}5 \mathrm{~min} \\
2 \mathrm{~h} \\
4 \mathrm{~h}\end{array}$ & $\begin{array}{l}38 \pm 4 \\
40 \pm 5 \\
23 \pm 3\end{array}$ & $\begin{array}{r}15 \pm 3 \\
5 \pm 3 \\
0 \pm 0\end{array}$ & $\begin{array}{l}2 \pm 1 \\
0 \pm 0 \\
0 \pm 0\end{array}$ & $\begin{array}{l}53 \pm 2 \\
55 \pm 0 \\
55 \pm 0\end{array}$ & $\begin{array}{l}38 \pm 9 \\
42 \pm 6 \\
47 \pm 2\end{array}$ & $\begin{array}{l}35 \pm 3 \\
27 \pm 7 \\
22 \pm 6\end{array}$ \\
\hline Egg yolk-Tris-fructose & $\begin{array}{l}5 \mathrm{~min} \\
2 \mathrm{~h} \\
4 \mathrm{~h}\end{array}$ & $\begin{array}{l}42 \pm 4 \\
45 \pm 8 \\
40 \pm 10\end{array}$ & $\begin{array}{l}18 \pm 2 \\
37 \pm 7 \\
20 \pm 6\end{array}$ & $\begin{array}{l}5 \pm 0 \\
5 \pm 0 \\
0 \pm 0\end{array}$ & $\begin{array}{l}62 \pm 1 \\
60 \pm 3 \\
58 \pm 3\end{array}$ & $\begin{array}{l}50 \pm 0 \\
53 \pm 2 \\
53 \pm 2\end{array}$ & $\begin{array}{l}43 \pm 3 \\
53 \pm 4 \\
48 \pm 4\end{array}$ \\
\hline
\end{tabular}

(a) Proportion of motile spermatozoa with SAR based on a scale of $0-3(0=<5 \%, 1=5-25 \%, 2=26-50 \%$, and 3 $\geqslant 50 \%$. Mean score for 3 replicates. ${ }^{*} n=2$, no motile spermatozoa in one replicate. $\dagger$ No motile spermatozoa to evaluate.

(b) Values are mean \pm s.e.m. for 3 observations.

very few spermatozoa developed SAR at any storage or incubation interval. When egg yolk-citrate stored spermatozoa were extended and incubated with egg yolk-Tris-fructose, there was a substantial increase in SAR with increased duration of storage and incubation, thus accounting for the significant three-way interaction. The SAR response reached a maximum level after 5 days storage $\left(4^{\circ} \mathrm{C}\right)$ in egg yolk-citrate and $2 \mathrm{~h}$ of incubation at $37^{\circ} \mathrm{C}$ in egg yolk-Tris-fructose.

For motility (Table $1 \mathrm{~b})$ an interaction $(P<0.01)$ existed for the effects of storage medium, length of storage, incubation medium, and length of incubation. Motility of spermatozoa stored in seminal plasma followed by incubation in egg yolk-citrate decreased rapidly with storage and/or incubation. Incubation in egg yolk-Tris-fructose improved motility after storage in seminal plasma but a precipitous decline with storage was still evident. If seminal plasma was replaced with egg yolk-citrate, the percentage motile spermatozoa was substantially improved. Little change with incubation was noted. Motility was best after storage in egg yolk-citrate and subsequent incubation in egg yolk-Tris-fructose. SAR was therefore associated with conditions that supported high as well as low levels of motility.

\section{Discussion}

Ultrastructural investigation confirmed that the SAR observed on motile spermatozoa using differential interference-contrast microscopy was due to localized expansions of the acrosomal matrix. Also, outer acrosomal and plasma membrane integrity was retained despite the complex change in acrosomal morphology. The outer acrosomal membrane apparently expanded to cover the increase in acrosomal surface area. Since the plasma membrane was intact and SAR did not correspond to motility loss, SAR does not appear to be a phase of the false acrosome reaction as described by Saacke \& Marshall (1968).

Swelling of the anterior acrosome has been observed for the spermatozoa of bulls and other males. Jones \& Stewart (1979) observed a subtle swelling of the anterior acrosome after cooling to 
$5^{\circ} \mathrm{C}$ and after cryopreservation of bovine spermatozoa. The affected semen had normal fertility (Linford, Glover, Bishop \& Stewart, 1976) suggesting to Jones \& Stewart (1979) that this acrosomal change was possibly related to the true acrosome reaction. A similar acrosomal change was reported by Pace et al. (1981) after cryopreservation of bovine spermatozoa and they felt it might reflect cell injury. Motile boar spermatozoa can develop swollen apical ridges during ambient temperature $\left(15\right.$ or $25^{\circ} \mathrm{C}$ ) storage for artificial insemination (Pursel, Johnson \& Rampacek, 1972). However, strongly affected sperm populations were not fertile (Pursel, Johnson \& Schulman, 1972). Storage of ram spermatozoa at $5^{\circ} \mathrm{C}$ was shown ultrastructurally to cause acrosomal swelling without loss of plasma membrane or acrosomal membrane integrity (Jones \& Martin, 1973). This structural change was considered sufficient to account for the impairment of fertility which was found after semen storage under similar conditions.

In contrast to the false acrosome reaction of deteriorating spermatozoa, Yanagimachi \& Usui (1974) and Green (1978) indicated that there was a general swelling of the anterior acrosome of the guinea-pig before the true acrosome reaction. Yanagimachi \& Noda (1970) reported that the hamster acrosome appeared swollen and wrinkled before the true acrosome reaction. However, Talbot, Summers, Hylander, Keough \& Franklin (1976) described the guinea-pig acrosome as being crenulated before the true acrosome reaction. Comparable observations have been made on motile and fixed hamster spermatozoa (Franklin, Barros \& Fussel, 1970; Talbot \& Franklin, 1976).

In the present study, the condition most conducive to SAR was storing spermatozoa at $4^{\circ} \mathrm{C}$ as neat semen, i.e. in seminal plasma at $1500 \times 10^{6}$ spermatozoa $/ \mathrm{ml}$. However, dilution and incubation in egg yolk-Tris-fructose but not egg yolk-citrate replaced the necessity of storing spermatozoa in seminal plasma. A comparison of egg yolk-Tris-fructose with egg yolk-citrate and seminal plasma indicates that the active factors in egg yolk-Tris-fructose and seminal plasma may be fructose and/or amines. Both are abundant in bovine seminal plasma (Mann, 1964). However, the specific cause of SAR is still unknown.

The egg-yolk extenders studied have been used frequently in the artificial insemination industry and a common semen processing practice is to hold bovine semen in partly extended form (1 part semen $/ 1-5$ parts extender) at $30^{\circ} \mathrm{C}$ for up to $30 \mathrm{~min}$ and then cool slowly (over $1-3 \mathrm{~h}$ ) to $4^{\circ} \mathrm{C}$ for further processing. It is therefore likely that SAR occurs under current field conditions in artificial insemination. The swelling of the apical ridge of bull spermatozoa could be a unique form of sperm deterioration or a form of acrosomal change before the true acrosome reaction. A further understanding of the phenomenon is necessary for proper interpretation of acrosomal morphology as it is currently used in sperm viability determination.

We thank Judy Bame and June Mullins for their technical assistance with this research.

\section{References}

Aalseth, E.P., Senger, P.L. \& Becker, W.C. (1978) The relationship of sperm viability and concentration to serum-induced head-to-head agglutination of bovine spermatozoa. J. Reprod. Fert. 53, 193-196.

Almquist, J.O. \& Landa, C.A. (1980) Freezing bull semen in French straws in large numbers in a mechanical freezer. Proc. 8th Tech. Conf. Artif. Insem. Reprod., Natl. (U.S.) Ass. Anim. Breeders, Milwaukee, pp. 2124.

Bedford, J. M. (1970) Sperm capacitation and fertilization in mammals. Biol. Reprod., Suppl. 2, 128-158.

Franklin, L.E., Barros, C. \& Fussel, E.N. (1970) The acrosomal region and the acrosome reaction in sperm of the golden hamster. Biol. Reprod. 3, 180-200.

Goodnight, J.H. (1979) GLM procedure. In SAS User's
Guide, pp. 237-244. Eds J. T. Helwig \& K. A. Council. SAS Institute, Raleigh.

Green, D.P.L. (1978) The induction of the acrosome reaction in guinea-pig sperm by the divalent metal cation ionophore A23187. J. Cell Sci. 32, 137-151.

Johnson, L., Berndtson, W.E. \& Pickett, B.W. (1976) An improved method for evaluating acrosomes of bovine spermatozoa. J. Anim. Sci. 42, 951-954.

Jones, R.C. \& Martin, I.C.A. (1973) The effects of dilution, egg yolk and cooling to $5^{\circ} \mathrm{C}$ on the ultrastructure of ram spermatozoa. J. Reprod. Fert. $35,311-320$.

Jones, R.C. \& Stewart, D.L. (1979) The effects of cooling to $5^{\circ} \mathrm{C}$ and freezing and thawing on the ultrastructure of bull spermatozoa. J. Reprod. Fert. 56, 233-238. 
Karnovsky, M.J. (1965) A formaldehyde glutaraldehyde fixative of high osmolarity for use in electron microscopy. J. Cell Biol. 27, 137a, abstr.

Linford, E., Glover, F.A., Bishop, C. \& Stewart, D.L. (1976) The relationship between semen evaluation methods and fertility in the bull. J. Reprod. Fert. 47, 283-291.

Mann, T. (1964) The Biochemistry of Semen and of the Male Reproductive Tract, 2nd edn, pp. 94-100. Methuen, London.

Mitchell, J.R., Hanson, R.D. \& Fleming, W.N. (1978) Utilizing differential interference contrast microscopy for evaluating abnormal spermatozoa. Proc. 7th Tech. Conf. Artif. Insem. Reprod., Natl. (U.S.) Ass. Anim. Breeders, Milwaukee, pp. 64-68.

Pace, M.M., Sullivan, J.J., Elliott, F.I., Graham, E.F. \& Coulter, G.H. (1981) Effects of thawing temperature, number of spermatozoa and spermatozoal quality on fertility of bovine spermatozoa packaged in $.5 \mathrm{ml}$ French straws. J. Anim. Sci. 53, 693-701.

Pursel, V.G., Johnson, L.A. \& Rampacek, G.B. (1972) Acrosome morphology of boar spermatozoa incubated before cold shock. J. Anim. Sci. 34, 278-283.

Pursel, V.G., Johnson, L.A. \& Schulman, L.L. (1972) Loss of boar sperm fertilizing capacity associated with altered acrosome morphology during in vitro storage. Proc. 7th Int. Congr. Anim. Reprod. \& A.I., Munich 2, 1595-1600.

Robbins, R.K., Saacke, R.G. \& Chandler, P.T. (1976) Influence of freeze rate, thaw rate and glycerol level on acrosomal retention and survival of bovine spermatozoa frozen in French straws. J. Anim. Sci. 42, 145-154.
Saacke, R.G. \& Marshall, C.E. (1968) Observations on the acrosomal cap of fixed and unfixed bovine spermatozoa. J. Reprod. Fert. 16, 511-514.

Saacke, R.G. \& White, J.M. (1972) Semen quality tests and their relationship to fertility. Proc. 4 th Tech. Conf. Artif. Insem. and Reprod., Natl. (U.S.) Ass. Anim. Breeders, Chicago, pp. 22-27.

Saacke, R.G., Marshall, C.E., Vinson, W.E., O'Connor, M.L., Chandler, J.E., Mullins, K.J., Amann, R.P., Wallace, R.A., Vincel, W.N. \& Kellgren, H.C. (1980) Semen quality and heterospermic insemination in cattle. Proc. 9th Int. Congr. Anim. Reprod. \& A.I., Madrid 5, 75-78.

Simionescu, N. \& Simionescu, M.(1976) Galloyl glucoses of low molecular weight as mordants in electron microscopy. I. Procedure and evidence for mordanting effect. J. Cell Biol. 70, 608-621.

Talbot, P. \& Franklin, L.E. (1976) Morphology and kinetics of the hamster sperm acrosome reaction. $J$. exp. Zool. 198, 163-176.

Talbot, P., Summers, R.G., Hylander, B.L., Keough, E.M. \& Franklin, L.E. (1976) The role of calcium in the acrosome reaction: An analysis using ionophore A23187. J. exp. Zool. 198, 383-392.

Venable, J.H. \& Coggeshall, R. (1965) A simplified lead citrate stain for use in electron microscopy. J. Cell Biol. 25, 407-408.

Yanagimachi, R. \& Noda, Y.D. (1970) Ultrastructural changes in the hamster sperm head during fertilization. J. Ultrastruct. Res. 31, 465-485.

Yanagimachi, R. \& Usui, N. (1974) Calcium dependence of the acrosome reaction and activation of guinea pig spermatozoa. Expl Cell Res. 89, 161-174.

Received 3 September 1984 